\title{
Externalising problems and environmental stressors predict adolescent problems in children from divorced families
}

Dawson-McClure SR, Sandler IN, Wolchik SA, et al. Risk as a moderator of the effects of prevention programs for children from divorced families: a six-year longitudinal study. J Abnorm Child Psychol 2004;32:175-90.

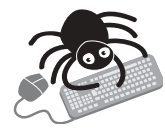

\section{Which variables predict adolescent problems in children from divorced families?}

\section{METHODS}

$\square$

Design: Longitudinal study.

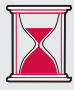

Follow up period: Six years.

Setting: Arizona, USA; timeframe not stated

으 People: 68 children (aged 9-12 years, primarily white and from middle income families) who were a control group of a larger RCT. Exclusions: depression; suicidal thoughts; living with mother for less than $50 \%$ of the time; receiving special education services; not taking medication if diagnosed with attention deficit disorder child, mother, or both receiving psychological treatment anticipated changes to custody; mother remarried, planning to remarry or had live-in boyfriend; living more than one hour drive from intervention site; and parents granted a divorce more than two years before enrolment.

$\Delta$

Risk factors: Both children and mothers were given three books on divorce adjustment to read over a six week period. Data on nine childhood predictors (easy temperament, positive coping, negative cognitions, competence, internalising and externalising problems, mother-child relationship quality, effective discipline, and environmental stressors) were measured at interview before the reading programme and at six years.

Outcomes: Internalising and externalising problems; competence; substance use; number of sexual partners; and diagnosis of mental disorder.

\section{MAIN RESULTS}

At six years, childhood environmental stressors and externalising problems were significant predictors of adolescent problems in children from divorced families (see http://www.ebmentalhealth $\mathrm{com} /$ supplemental for table). Externalising problems in childhood strongly predicted internalising problems, competence, and substance use, and weakly predicted mental disorder in adolescence. Environmental stressors in childhood strongly predicted externalising problems and weakly predicted internalising problems, competence, and mental disorder in adolescence. Internalising problems in childhood weakly predicted internalising problems in adolescence. When a single risk index, comprising childhood externalising problems and environmental stressors, was used as a predictor in regression analysis, risk was significantly related to internalising problems, externalising problems, competence and substance use. A risk index score of 0.3 was identified as the optimal cut off point by receiver operating characteristic (ROC) curve analysis (sensitivity: 0.75 ; specificity: 0.73 ). The odds ratio for mental disorder was 8.14 for the group above this cut off point. Using this risk index as a predictor of adolescent outcomes, reanalysis of the original randomised controlled trial study data showed that preventative For correspondence: Spring Dawson-McClure, Department of Psychology, Arizona State University, Tempe, Arizona, USA; spring.dawson@asu.edu Sources of funding: the National Institute of Mental Health. interventions provided the most benefit for children that were at high risk of adolescent problems.

\section{CONCLUSIONS}

A risk index comprising externalising problems and environmental stressors significantly predicted adolescent problems in children from divorced families. This risk index could help to identify children at high risk of adolescent problems that would benefit most from preventative interventions.

\section{Commentary} C tudies of interventions for children at risk of developing serious

S tell us about the usefulness of intervening before the emergence of clinical disturbance and for what they can tell us about the modifiability of the link between risk exposure (such as parental divorce) and psychological disturbance. Several groups have developed interventions for children who experienced parental divorce. ${ }^{12}$ The current study, which expands a previous report, ${ }^{3}$ asks for whom are interventions most effective. This is such an important topic for clinical research because there are, to use Hetherington's phrase, " "winners, losers, and survivors" among family members experiencing a divorce. We would hardly expect all children experiencing parental divorce to show adjustment problems. Accordingly, we should hardly expect that children exposed to divorce would similarly respond to an intervention.

Dawson-McClure and colleagues conducted an intervention for 9-12 year old children experiencing parental divorce in the two years before the intervention. At six years follow up, they found that the intervention was especially likely to have prevented problems in children at greater psychosocial risk before the intervention started. For those children at low levels of risk, the effect of the intervention was undetectable.

Three applications are worth emphasising. Firstly, the study considered a range of developmental outcomes, including mental disorder and academic and peer competence-a necessary step given that the effects of parental divorce are not specific. Secondly, the definition of who was most at risk was derived from a composite of pre-existing behavioural problems and environmental stresses. That means that identifying those most likely to benefit may not always be straightforward. Finally, the intervention was modest in scope, consisting of a manualised programme of 11 group and two individual sessions in which mothers were assisted in improving parent-child relationship quality and effective discipline, reducing interparental conflict, and increasing father access (interestingly, the addition of a child component for some children did not add significant benefits to the mother programme alone). Thus, effective means of meeting the needs of at-risk children does not always require extensive and very costly services.

Thomas G O'Connor, PhD

University of Rochester Medical Center, Rochester, NY, USA

1 Forgatch M, DeGarmo DS. Parenting through change: an effective prevention program for single mothers. J Consult Clin Psychol 1999;67;711-24.

2 Pedro-Carroll JL, Cowen EL, Hightower AD, et al. Preventive intervention with latency-aged children of divorce: a replication study. Am J Community Psychol 1986;14:277-90

3 Wolchik SA, Sandler IN, Millsap RE, et al. Six-year follow-up of preventive interventions for children of divorce: a randomized controlled trial. JAMA 2002;288:1874-81.

4 Hetherington EM. Coping with family transitions: winners, losers and survivors. Child Dev 1989;60:1-14 